DOI: https://doi.org/10.47405/mjssh.v6i1.612

\begin{tabular}{|c|c|}
\hline 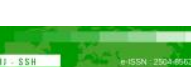 & Malaysian Journal of Social Sciences and Humanities (MJSSH) \\
\hline Malaysian Journal of & Volume 6, Issue 1, January 2021 \\
\hline (MJ-ssH) & e-ISSN : 2504-8562 \\
\hline & $\begin{array}{l}\text { Journal home page: } \\
\text { www.msocialsciences.com }\end{array}$ \\
\hline
\end{tabular}

\title{
Pendekatan Kebolehsuaian Kerjaya dalam kalangan Pelajar Kolej Vokasional di Selangor
}

\author{
Zulhazmi Zahari', Muhd Khaizer Omar' \\ 1Fakulti Pengajian Pendidikan, Universiti Putra Malaysia (UPM) \\ Correspondence: Zulhazmi Zahari (hazmiey3201@yahoo.com)
}

\begin{abstract}
Abstrak
Perubahan teknologi yang drastik disebabkan oleh perkembangan Revolusi Perindustrian 4.0 secara tidak langsung memberi impak kepada pembangunan negara dan trend pekerjaan. Keadaan ini telah menimbulkan kebimbangan dalam kalangan graduan pendidikan terutamanya dalam aliran Pendidikan dan Latihan Teknikal dan Vokasional (PLTV) untuk memenuhi keperluan perindustrian. Secara amnya, para graduan menerima kritikan kerana prestasi yang kurang memberangsangkan ketika memasuki alam pekerjaan. Keadaan ini mendatangkan masalah yang serius dalam perbincangan meja bulat terutama isu-isu yang berkaitan dengan kelayakan siswazah, kemahiran pekerjaan, dan kurangnya penyertaan dalam industri. Walau bagaimanapun, aliran PLTV telah diberikan perhatian yang serius apabila pembudayaan politik dan tindakan proaktif kerajaan yang berusaha meningkatkan jumlah pekerja mahir dalam negara Artikel ini merungkaikan kebolehsuaian kerjaya sebagai faktor utama dalam menyelaraskan kesediaan tenaga kerja dengan landskap pekerjaan graduan. Perbincangan ini membawa kepada pemahaman perkembangan dimensi kebolehsuaian kerjaya dalam kalangan pelajar kolej vokasional di Malaysia. Hubungan antara pemboleh ubah yang dinyatakan merangkumi penerimaan sokongan sosial dan kebolehsuaian kerjaya turut dikaji. Penyelidikan ini dijalankan dengan menggunakan pendekatan kuantitatif dengan melengkapkan set set soal selidik dan diedarkan kepada 226 orang pelajar diploma tahun akhir dalam enam program pengajian yang didaftarkan dengan menggunakan teknik persampelan bertujuan. Statistik deskriptif dan inferens telah digunakan menggunakan SPSS Versi 23 untuk memperoleh hubungan berdasarkan persoalan kajian. Pemahaman terhadap hala tuju masa hadapan dapat membantu graduan memahami hubungan yang mungkin wujud antara kebolehsuaian kerjaya dengan pemboleh ubah yang disebutkan bagi mencadangkan penambahbaikan untuk menggalakkan pelaksanaan kurikulum PLTV dalam memberi jaminan kebaikan kepada graduan negara bermula daripada peringkat akar umbi.
\end{abstract}

Kata kunci: kebolehsuaian kerjaya, pendidikan dan latihan teknikal dan vokasional, penerimaan sokongan sosial

\section{Career Adaptability Approach Among Vocational College Students in Selangor}

\begin{abstract}
Drastic technological changes due to the development of the Industrial Revolution 4.0 indirectly impacted national development and employment trends. This situation has raised concerns among education graduates especially in the stream of Technical and Vocational Education and Training (TVET) to meet the needs of industry. Generally, graduates receive criticism for poor performance when entering the world of work. This situation poses a serious problem in roundtable discussions
\end{abstract}


especially issues related to graduate qualifications, job skills, and lack of participation in the industry. However, the TVET stream has been given serious attention when it comes to the political culture and proactive actions of the government which seeks to increase the number of skilled workers in the country. This article describes career adaptability as a key factor in aligning the readiness of the workforce with the graduate work landscape. This discussion leads to an understanding of the development of career adaptability dimensions among vocational college students in Malaysia. The relationship between the stated variables including acceptance of social support and career adaptability was also studied. This research was conducted using a quantitative approach by completing a set of questionnaires and distributed to 226 final year diploma students in six programs of study registered using purposeful sampling techniques. Descriptive and inference statistics were used using SPSS Version 23 to obtain relationships based on research questions. Understanding the future direction can help graduates understand the possible relationship between career adaptability and the variables mentioned to suggest improvements to encourage the implementation of the TVET curriculum in ensuring benefits to national graduates starting from the grassroots level.

Keywords: career adaptability, technical and vocational education and training, perceived social support

\section{Pengenalan}

Sejak kebelakangan ini, terdapat minat yang tinggi terhadap kajian kebolehsuaian kerjaya sebagai konstruk psikososial. Berdasarkan teori pembinaan kerjaya, kebolehsuaian kerjaya menjurus kepada kesediaan untuk menghadapi tugas, peralihan, dan trauma yang berkaitan dengan kerjaya yang dijangka dan tidak dijangka (Savickas, 2011). Dalam dunia pekerjaan masa kini yang sentiasa berubah, kebolehsuaian adalah sikap yang perlu dimiliki oleh semua pekerja. Hal ini membolehkan individu untuk mengekalkan kebolehpasaran dan menghadapi peralihan dalam kerjaya mereka (Hirschi, Herrmann, \& Keller, 2015; Savickas et al., 2009).

Kebolehsuaian kerjaya dapat ditakrifkan mengikut empat kekuatan kendiri yang merangkumi keprihatinan, kawalan, Perasaan ingin tahu, dan keyakinan. Keprihatinan merujuk kepada pandangan dan perancangan kerjaya pada masa hadapan. Kawalan mencerminkan aspek pemilikan dan akauntabiliti dalam membuat keputusan dan membina kerjaya masa hadapan seseorang. Perasaan ingin tahu menerangkan proses penerokaan untuk mendapatkan maklumat mengenai peluang pekerjaan, berdasarkan kekuatan dan minat individu itu sendiri. Akhir sekali, keyakinan merujuk kepada kebolehan seseorang dalam membuat keputusan, tugas dan peralihan yang berkaitan dengan kerjaya (Porfeli \& Savickas, 2012).

Peralihan daripada alam persekolahan ke alam pekerjaan adalah salah satu cabaran besar yang harus dihadapi oleh semua graduan apabila mereka melangkah dalam bidang kerjaya serta dapat menyesuaikan diri dengan peranan kerja masing-masing (Savickas, 1999). Individu ini mungkin mendapat kemahiran dan strategi yang sedia ada tetapi tidak cukup untuk menyokong peralihan yang dialami oleh mereka sekarang. Laluan para graduan untuk menceburi bidang kerjaya sememangnya tidak dapat diramal (Gelatt, 1989). Pada masa yang sama, mereka yang boleh merancang laluan kerjaya dengan baik dapat menghadapi halangan dan menyesuaikan diri dalam pelbagai situasi. Bagi mencapai kejayaan dalam peralihan ini, pusat pengajian mesti dapat menentukan hala tuju kerjaya (keprihatinan), bertanggungjawab terhadap pilihan kerjaya mereka (kawalan), terbuka untuk meneroka peluang kerjaya (perasaan ingin tahu), dan tetap cekal dalam mengejar aspirasi kerjaya mereka walaupun menghadapi masalah (keyakinan).

\section{Perubahan Struktur Kerjaya}

Perkembangan teknologi dan pembangunan manusia sentiasa dikaitkan dengan perubahan berterusan atas persekitaran dan peranan serta struktur pekerjaan. Identiti seseorang individu biasanya dibentuk 
bermula zaman kanak-kanak dan akan terus berkembang dalam komuniti dan persekitaran mereka. Dalam situasi ini, persekitaran sekolah dapat mempersiapkan individu untuk menghadapi dunia pekerjaan (Savickas, 2013). Keperibadian adalah satu aspek yang menentukan keupayaan kerjaya, minat, nilai, dan keperluan. Individu yang mempunyai keperibadian yang tinggi mempunyai asas yang kukuh untuk menceburi apa-apa pekerjaan dan bidang kerjaya. Kerjaya bertindak sebagai perantara antara kehidupan seseorang dan masyarakat di luar (Parker, 2002). Hubungan ini bertindak sebagai perantara yang penting bagi seseorang individu yang ingin membuat perubahan melalui pekerjaan atau kerjaya yang dipilih. Menurut Sullivan dan Baruch (2009), kerjaya boleh ditakrifkan sebagai hubungan individu dengan organisasi pekerjaan. Perubahan berterusan dalam norma kerjaya telah membawa kepada istilah baharu seperti ‘kerjaya tanpa sempadan' yang dianggap lebih relevan dengan abad ke21. Perubahan struktur telah menjana keperluan bagi pekerja untuk memiliki kemahiran kebolehsuaian kerjaya yang dapat membantu mereka menyesuaikan diri dengan perubahan kerjaya (Ebenehi, Rashid \& Bakar, 2016). Fenomena ini juga telah mengubah organisasi untuk menjadi lebih fleksibel berbanding sebelum ini iaitu peningkatan kerjaya adalah berdasarkan peningkatan hierarki di dalam organisasi. Tanggapan ini telah berubah di mana peningkatan kerjaya adalah lebih ditentukan oleh aspirasi dan inspirasi individu (Dickmann \& Doherty, 2008). Walau bagaimanapun, pada masa ini, penentu utama pasaran kerja ialah ekonomi yang dipacu oleh pengetahuan dan teknologi baharu serta pasaran global.

Teknologi telah mengubah pekerjaan, persekitaran, dan kemahiran yang diperlukan dalam setiap pekerjaan untuk membolehkan seorang pekerja bekerja dengan baik (Ajake, Oba, \& Ekpo 2014). Perubahan dalam struktur pekerjaan telah mengubah peranan organisasi dan dijangka akan membawa lebih banyak perubahan. Sehubungan itu, pekerja hendaklah mempunyai kemahiran penyesuaian kerjaya untuk menyesuaikan diri dengan keperluan pekerjaan baharu selaras dengan perubahan persekitaran kerja dan kehadiran teknologi baru seperti alat dan mesin yang akan mengurangkan kebergantungan terhadap tenaga fizikal (Hartung, Porfeli \& Vondareck, 2008). Tidak dapat dinafikan, perubahan ini telah membawa cabaran baharu dalam bidang pembangunan kerjaya. Di samping itu, kemajuan teknologi maklumat dan komputer (ICT) telah mengurangkan keperluan tenaga kerja secara drastik dalam pasaran pekerjaan (Obi, Oye, Mohd, \& Bernice, 2012). Kehadiran teknologi baharu dan perubahan landskap ekonomi telah mewujudkan peluang kerjaya baharu yang menggambarkan keperluan pengetahuan baharu dan kemahiran menyesuaikan diri agar seseorang pekerja dapat bekerja dengan lebih baik. Perubahan struktur kerja organisasi yang berterusan juga telah membawa kepada perubahan landskap ekonomi global. Oleh itu, majikan dan pekerja perlu melengkapkan diri dengan kemahiran penyesuaian kerjaya. Kajian telah menunjukkan bahawa dalam model pekerjaan tradisional, kemahiran kerjaya dan pengurusan diri adalah tertumpu kepada kemahiran berasaskan hierarki (Ebberwein, Krieshok, Ulven \& Prosser, 2004). Namun menurut Rashid (2011), kemahiran kerja pada masa ini telah tertumpu kepada kemahiran praktikal dan komunikasi dalam industri yang tidak dapat diajar di dalam bilik darjah. Beliau juga menegaskan bahawa keperluan pekerjaan pada masa hadapan akan lebih bergantung kepada penyesuaian kerjaya dan keperluan pasaran kerja berbanding kelayakan akademik. Perubahan struktur kerjaya pada masa ini menunjukkan keperluan kemahiran kebolehsuaian kerjaya yang membolehkan pelajar Pendidikan dan Latihan Teknikal dan Vokasional untuk menyesuaikan diri dalam dunia ekonomi yang sentiasa berubah.

\section{Penerimaan Sokongan Sosial Terhadap Kebolehsuaian Kerjaya}

Tanggapan penerimaan sokongan sosial merujuk kepada tanggapan individu mengenai faktor yang berkaitan dengan rangkaian sosial mereka dan sokongan peribadi yang diterima (Canty-Mitchell \& Zimet, 2000). Ibu bapa, rakan, guru, dan individu lain mempengaruhi perkembangan minat, nilai kerja, dan kerjaya seseorang (Josselson, 1994). Mereka menawarkan sokongan dan galakan serta dapat membantu seseorang membuat keputusan penting dalam hidup mereka. Kajian di Amerika Syarikat (Kenny \& Bledsoe, 2005) dan Korea Selatan (Han \& Rojewski, 2015) telah mengkaji peranan sokongan sosial yang diperoleh daripada guru, kawan rapat, dan keluarga dalam meramalkan kesediaan kerjaya, perancangan kerjaya dan penerokaan kerjaya dalam kalangan pelajar sekolah menengah. Kajian dalam subjek yang sama juga dijalankan oleh Hirschi (2009) terhadap pelajar di Switzerland. Kajian tersebut mendapati bahawa pelajar yang menerima sokongan sosial yang lebih kerap daripada 
ibu bapa dapat menunjukkan kebolehsesuaian kerja yang lebih tinggi. Wang dan Fu (2015) juga mengesahkan bahawa sokongan sosial daripada rakan sekolah mempunyai hubungan positif dengan kebolehsesuaian kerjaya dalam kalangan sekumpulan pelajar kolej di China.

Walau bagaimanapun, kajian daripada Mahamud, Hassan dan Fakhruddin (2018), hubungan yang tidak signifikan antara sokongan ibu bapa dengan keputusan akademik anak-anak mereka telah ditunjukkan dalam analisis Korelasi Pearson. Hal ini demikian kerana ibu bapa tidak aktif melibatkan diri dalam aktiviti yang dijalankan oleh pihak sekolah. Namun, Malik (2020) meyakini bahawa komunikasi positif antara ibu bapa dan pihak sekolah memberikan banyak faedah kepada semua pihak.

Kajian yang dijalankan oleh Hlado, et al., (2019) atas seramai 3028 orang pelajar lepasan sekolah menengah atas di Republik Czech menunjukkan terdapat hubungan yang positif antara sokongan sosial yang terdiri daripada ahli keluarga, rakan-rakan dan pihak lain yang terlibat dengan kebolehsuaian kerjaya. Keempat-empat konstruk kebolehsuaian kerjaya tersebut menunjukkan nilai kolerasi antara 0.47 hingga 0.62 .

Secara umumnya kajian ini bertujuan mengkaji kebolehsuaian kerjaya dalam kalangan pelajar yang mengambil program diploma tahun akhir di Kolej Vokasional di seluruh Selangor. Objektif secara khusus adalah:

i. Mengenal pasti latar belakang responden dari segi jantina.

ii. Mengenal pasti latar belakang responden dari segi bidang pengajian.

iii. Mengenal pasti hubungan penerimaan sokongan sosial dengan konstruk keprihatinan, kawalan, perasaan ingin tahu dan keyakinan dalam kebolehsuaian kerjaya.

\section{Metod Kajian}

Penyelidikan ini mengambil pendekatan kuantitatif dalam pelaksanaan kajiannya iaitu melalui kaedah tinjauan dengan menjadikan soal selidik sebagai medium pengumpulan data untuk mengenal pasti aspek yang boleh mempengaruhi pemboleh ubah kajian (Gay \& Airasian, 2003; Creswell, 2014). Antara sebab kaedah tinjauan dipilih dalam kajian ini adalah kerana kesesuaiannya dengan situasi penyelidikan yang akan dilaksanakan pada satu-satu masa yang tertentu sahaja selain daripada pemerolehan maklumat deskriptif yang sangat berkesan dan memuaskan. Selain itu, kajian ini memilih kaedah tinjauan kerana jumlah sampel kajian lebih besar yang menjadikan penggunaan soal selidik piawai dalam proses mengumpul data adalah lebih praktikal dan relevan (Gay \& Arasian, 2003). Dalam soal selidik ini pula, pengkaji telah mengguna pakai skala lima mata (five point scale). Pengkaji juga dapat mengenal pasti ketekalan pemboleh ubah yang terdapat dalam kajian yang berbentuk deskriptif-korelasi ini (Sekaran, 2003). Pengkaji menganalisis data secara kuantitatif dengan menggunakan Perisian Statiscal Package for the Social Sciences (SPSS) versi 23.

Penglibatan dalam kajian ini adalah melibatkan pelajar tahun akhir yang mengikuti program yang ditawarkan oleh kolej vokasional. Seramai 122 pelajar lelaki (54\%) dan seramai 104 (46\%) yang berumur 19 tahun merangkumi bidang teknologi kejuruteraan elektrik dan elektronik (8.8\%), teknologi kejuruteraan awam (4.0\%), teknologi kejuruteraan mekanikal dan pembuatan (33.2\%), perniagaan (28.8\%), teknologi maklumat dan komunikasi (10.6\%), dan hospitaliti serta pelancongan (14.6\%).

\section{Hasil Kajian}

Dapatan kajian menunjukkan tidak terdapat perbezaan yang signifikan dalam kebolehsuaian kerjaya bagi lelaki $(\mathrm{M}=4.1974, \mathrm{SP}=0.3444)$ dan lelaki $(\mathrm{M}=4.1202, \mathrm{SP}=0.03488 ; \mathrm{t}(224)=1.567, \mathrm{p}=0.119$ $>.05)$. 
Malaysian Journal of Social Sciences and Humanities (MJSSH), Volume 6, Issue 1, (page 52 - 60), 2021

DOI: https://doi.org/10.47405/mjssh.v6i1.612

Jadual 1: $t$-test antara kebolehsuaian kerjaya dengan jantina

\begin{tabular}{lllllll}
\hline Kumpulan & $\begin{array}{l}\text { Bilangan } \\
\text { Pelajar }\end{array}$ & Min & $\begin{array}{l}\text { Sisihan } \\
\text { Piawai }\end{array}$ & Nilai $\boldsymbol{t}$ & $\begin{array}{l}\text { Darjah } \\
\text { Kebebasa } \\
\text { n }\end{array}$ & Signifikan \\
\hline Lelaki & 122 & 4.1974 & .03444 & 1.567 & 224 & .119 \\
Perempuan & 104 & 4.1202 & .03488 & 1.575 & 222.056 & .117 \\
\hline
\end{tabular}

Analis ANOVA satu hala menunjukkan tidak terdapat perbezaan yang signifikan antara min bidang pengajian $[\mathrm{F}(5,225)=1.473, \mathrm{p}=.200>.05]$ bagi kebolehsuaian kerjaya mengikut bidang yang diambil oleh pelajar. Oleh itu hipotesis tidak dapat ditolak. Hal ini menunjukkan bahawa pelajar daripada semua bidang tidak mempunyai perbezaan dari segi kebolehsuaian kerjaya.

Jadual 2: Analisis ANOVA

\begin{tabular}{lccccc}
\hline & $\begin{array}{c}\text { Jumlah kuasa } \\
\text { dua }\end{array}$ & $\begin{array}{c}\text { Darjah } \\
\text { kebebasan }\end{array}$ & $\begin{array}{c}\text { Min Kuasa } \\
\text { Dua }\end{array}$ & F & $\begin{array}{c}\text { Signifik } \\
\text { an }\end{array}$ \\
\hline Antara Kumpulan & 1.000 & 5 & .200 & 1.47 & .200 \\
Dalam Kumpulan & 29.877 & 220 & .136 & 3 & \\
Jumlah & 30.877 & 225 & & & \\
\hline
\end{tabular}

Analisis korelasi pearson menunjukkan terdapat hubungan signifikan yang positif antara konstruk keprihatinan dalam kebolehsuaian kerjaya dengan min penerimaan sokongan sosial $\left[\mathrm{N}=226, \mathrm{r}=.430^{* *}\right.$ $\mathrm{p}=0.01]$ dan hubungan ini adalah sederhana (Connolly \& Sluckin, 1971). Situasi ini menunjukkan bahawa konstruk keprihatinan dalam kebolehsuaian kerjaya mempunyai hubungan positif yang sederhana dengan penerimaan sokongan sosial.

Jadual 3: Ujian Korelasi Pearson bagi konstruk keprihatinan dalam kebolehsuaian kerjaya dengan min penerimaan sokongan sosial

\begin{tabular}{|c|c|c|c|}
\hline & $\begin{array}{l}\text { Min Penerimaan Sokongan } \\
\text { Sosial }\end{array}$ & Interpretasi Hubungan & \\
\hline Min Keprihatinan & $.430^{* *}$ & $\begin{array}{l}\text { Hubungan positif } \\
\text { sederhana }\end{array}$ & yang \\
\hline
\end{tabular}

Analisis korelasi pearson menunjukkan terdapat hubungan signifikan yang positif antara konstruk kawalan dalam kebolehsuaian kerjaya dengan min penerimaan sokongan sosial $\left[\mathrm{N}=226, \mathrm{r}=.382^{* *} \mathrm{p}=\right.$ 0.01] dan hubungan ini adalah sederhana (Connolly \& Sluckin, 1971). Hal ini menunjukkan bahawa konstruk kawalan dalam kebolehsuaian kerjaya mempunyai hubungan positif yang sederhana dengan penerimaan sokongan sosial.

Jadual 4: Ujian Korelasi Pearson bagi konstruk kawalan dalam kebolehsuaian kerjaya dengan min penerimaan sokongan sosial

\begin{tabular}{|c|c|c|c|c|}
\hline & $\begin{array}{l}\text { Min Penerimaan } \\
\text { Sosial }\end{array}$ & Sokongan & Interpretasi Hubungan & \\
\hline Min Kawalan & $.382^{* *}$ & & $\begin{array}{l}\text { Hubungan positif } \\
\text { sederhana }\end{array}$ & yang \\
\hline
\end{tabular}

Analisis korelasi pearson menunjukkan terdapat hubungan signifikan yang positif antara konstruk perasaan ingin tahu dalam kebolehsuaian kerjaya dengan min penerimaan sokongan sosial $[\mathrm{N}=226, \mathrm{r}=$ $.382^{* *} \mathrm{p}=0.01$ ] dan hubungan ini adalah lemah (Connolly \& Sluckin, 1971). Perkara ini menunjukkan 
DOI: https://doi.org/10.47405/mjssh.v6i1.612

bahawa konstruk perasaan ingin tahu dalam kebolehsuaian kerjaya mempunyai hubungan positif yang lemah dengan penerimaan sokongan sosial.

Jadual 5: Ujian Korelasi Pearson bagi konstruk perasaan ingin tahu dalam kebolehsuaian kerjaya dengan min penerimaan sokongan sosial

\begin{tabular}{cllll}
\hline & & $\begin{array}{l}\text { Min Penerimaan } \\
\text { Sosial }\end{array}$ & Sokongan & Interpretasi Hubungan \\
\hline $\begin{array}{c}\text { Min } \\
\text { Ingin } \\
\text { Tahu }\end{array}$ & Perasaan & $.247^{* *}$ & Hubungan positif yang lemah \\
\hline
\end{tabular}

Analisis korelasi pearson menunjukkan terdapat hubungan signifikan yang positif antara konstruk keyakinan dalam kebolehsuaian kerjaya dengan min penerimaan sokongan sosial $\left[\mathrm{N}=226, \mathrm{r}=.380^{* * *}\right.$ $\mathrm{p}=0.01]$ dan hubungan ini adalah sederhana (Connolly \& Sluckin, 1971). Situasi ini menunjukkan bahawa konstruk keyakinan dalam kebolehsuaian kerjaya mempunyai hubungan positif yang sederhana dengan penerimaan sokongan sosial.

Jadual 6: Ujian Korelasi Pearson bagi konstruk keyakinan dalam kebolehsuaian kerjaya dengan min penerimaan sokongan sosial

\begin{tabular}{|c|c|c|}
\hline & $\begin{array}{l}\text { Min Penerimaan Sokongan } \\
\text { Sosial }\end{array}$ & Interpretasi Hubungan \\
\hline Min Keyakinan & $.380^{* * *}$ & $\begin{array}{ll}\begin{array}{l}\text { Hubungan } \\
\text { sederhana }\end{array} & \text { positif } \\
\end{array}$ \\
\hline
\end{tabular}

\section{Perbincangan Kajian}

Kajian ini telah membuktikan bahawa penerimaan sokongan sosial yang diramalkan secara statistik mempengaruhi kemahiran kebolehsuaian kerjaya dalam kalangan pelajar kolej vokasional di Malaysia. Kajian juga mendapati bahawa tidak terdapat perbezaan yang signifikan dalam kebolehsuaian kerjaya. Kajian ini telah menambah ilmu pengetahuan yang sedia ada di Malaysia berkaitan proses pembangunan kerjaya dalam kalangan orang dewasa terutamanya pelajar pendidikan tinggi.

Antara pihak lain yang diakui kepentingan mereka dalam menentukan kebolehsuaian kerjaya para pelajar ialah kewujudan rakan atau sahabat. Di samping kaum keluarga, sahabat turut memainkan peranan yang penting dalam kehidupan para pelajar. Menurut Razak (2017), memiliki seorang sahabat baik atau lebih merupakan kelebihan bagi mereka kerana sahabat juga dikatakan mampu untuk menjadi pendengar yang setia dan sentiasa ada sekiranya mereka memerlukan. Sahabat yang baik akan membantu para pelajar dalam situasi-situasi genting seperti apabila mereka mempunyai masalah yang tidak dapat diselesaikan sendiri. Sokongan baik yang diterima mampu mempengaruhi para pelajar untuk lebih yakin dengan keputusan yang dibuat dan akan sentiasa berusaha untuk mencapai kejayaan dalam perubahan kerjaya (Öztemel \& Yıldız-Akyol, 2019).

Perkara ini juga telah mewujudkan kesedaran dan memberikan maklumat mengenai kemahiran penyesuaian kerjaya dalam kalangan pelajar pendidikan tinggi kerana hal ini amat penting kepada mereka. Walau bagaimanapun, batasan kajian ini adalah tidak melibatkan semua pelajar dalam bidang pengajian di kolej vokasional. Oleh sebab itu, langkah berhati-hati harus dilakukan dalam mendapatkan keputusan menganalisis ujian $t$ yang digunakan untuk analisis dari segi jantina terhadap konstruk yang terdapat dalam kebolehsuaian kerjaya. Di samping itu, analisis kolerasi pearson digunakan untuk menentukan hubungan antara pemboleh ubah. Analisis kolerasi pearson digunakan adalah kerana penyelidik berminat untuk memahami hubungan antara pemboleh ubah kajian ini (Creed and Fallon, 2009; Yousefi et al., 2013; Turan et al., 2014). Atas sebab-sebab tersebut, para penyelidik ingin mencadangkan bahawa kajian masa hadapan perlu dilakukan yang meliputi program akademik lain di institusi pengajian tinggi awam di Malaysia. Pada masa hadapan, penyelidik harus berusaha untuk 
menggunakan Multiple linear regression (MLR) untuk menganalisis supaya dapat menentukan keputusan peramal terbaik antara konstruk yang terdapat dalam kebolehsuaian kerjaya.

Di samping itu, kemahiran kebolehsuaian kerjaya tidak semestinya menunjukkan bahawa mereka akan menggunakan kemahiran tersebut dalam alam pekerjaan nanti. Dalam perkaitan ini, kebolehsuaian kerjaya juga penting untuk melakukan penyelidikan susulan kerjaya di tempat kerja berdasarkan pelajar yang telah bergraduasi. Tambahan pula, kajian ini perlu dijalankan di seluruh dunia, memandangkan kepentingannya akan membantu kemahiran menyesuaikan kerjaya bagi pelajar di institusi latihan kemahiran awam di Malaysia. Peningkatan dalam kebolehsuaian kerjaya dalam kalangan pelajar kolej vokasional akan meningkatkan penglibatan yang efektif oleh pelajar terhadap ekonomi dan secara tidak langsung mengurangkan kadar pengangguran. Aspek kurikulum dan amalan di Institusi Latihan kemahiran Awam di Malaysia haruslah menggalakkan pelajar pendidikan tinggi untuk meningkatkan kemahiran penyesuaian kerjaya mereka. Setiap institusi haruslah memberikan penekanan terhadap kebolehsuaian kerjaya dan kemahiran pelajar mereka secara lebih serius dengan menyediakan pangkalan data penerokaan kerjaya untuk mereka,serta menggalakkan program intervensi kerjaya menggunakan khidmat pakar kerjaya (Fraenkel et al., 2012).

\section{Kesimpulan}

Kajian ini telah dijalankan merujuk kepada kadar pengangguran yang sentiasa bertambah dalam kalangan graduan di Malaysia, terutamanya yang disebabkan oleh kurangnya kemahiran kebolehsuaian kerjaya, secara khususnya dalam kalangan pelajar PLTV (Statistik Pendidikan Tinggi, 2018). Selain itu, cabaran perubahan struktur kerja dan persekitaran yang sentiasa berubah, ditambah pula dengan persaingan yang tinggi dan keperluan pekerjaan, pelajar Pendidikan dan Latihan Teknikal dan Vokasional (PLTV) perlu bersiap sedia dengan keupayaan kebolehsuaian kerjaya supaya mereka dapat mengurus dan menyesuaikan diri.

Penerimaan sokongan sosial sama ada secara langsung mahupun tidak langsung daripada pelbagai pihak memberi kesan positif kepada pembentukan kemahiran kebolehsuaian kerjaya pelajar. Penglibatan semua pihak dalam memberi sokongan kepada pelajar menggambarkan bahawa sokongan dan dorongan dapat diterima daripada semua pihak yang ada di sekeliling mereka. Hal ini amat penting dalam mendorong mereka meningkatkan kemahiran kebolehsuaian kerjaya pada masa akan datang. Kemampuan semua pihak dalam memberikan sokongan kepada para pelajar dapat membantu memberikan penekanan tentang kepentingan kemahiran kebolehsuaian kerjaya kepada mereka. Secara tuntasnya, semua pihak yang terlibat perlu memainkan peranan untuk menerapkan kemahiran kebolehsuaian kerjaya dalam diri pelajar bagi meningkatkan potensi pelajar dalam dunia pekerjaan.

\section{Rujukan}

Ajake, U. E., Oba, A.N., Ekpo, T.E., (2014). Enriching Higher Education Curriculum to Meet the Challenges of 21st Century in Nigeria. Journal of Educational and Social Research, 4(3), 21-30. https://doi.org/10.5901/jesr.2014.v4n3p21

Canty-Mitchell, J., \& Zimet, G. (2000). Psychometric properties of the Multidimensional Scale of Perceived Social Support in urban adolescents. American Journal of Community Psychology, 28, 391-400.

Connolly, T. G., \& Sluckin, W. (1971). Measures of Variability. In An Introduction to Statistics for the Social Sciences (pp. 41-57). Palgrave Macmillan, London.

Creed, P. A., Fallon, T., \& H. M. (2009). The relationship between adaptability, person and situation variables, and career concerns in young adults. Journal of Vocational Behavior, 74(2), 219-229.

Creswell, J. W. (2014). Research design: Qualitative, quantitative and mixed methods approaches. Sage Publications, Inc.

Dickmann, M., \& Doherty, N. (2008). Exploring the career capital impact of international assignments within distinct organizational contexts. British Journal of Management,

$19(2), 145-161$. 
Ebberwein, C. A., Krieshok, T. S., Ulven, J. C., \& Prosser, E. C. (2004). Voices in transition: Lessons on career adaptability. The Career Development Quarterly, 52(4), 292-308. doi:10.1002/j.21610045.2004.tb00947.x

Ebenehi, A. S., Rashid, A. M., \& Bakar, A. R. (2016). Predictors of career adaptability skill among higher education students in Nigeria. International Journal for Research in Vocational Education and Training, 3, 212-229.

Fraenkel, J. R., Wallen, N. E., \& Hyun, H. H. (2012). How to design and evaluate research in education (8th ed.). New York: The McGraw-Hill Companies.

Gay, L. R., \&Airasian (2003). Educational Research: Competencies for Analysis and Applications (7th ed.). Upper Saddle River, NJ: Merrill/Prentice Hall.

Gelatt, H. B. (1989). Positive uncertainty: A new decision-making framework for counsel- ing. Journal of Counseling Psychology, 36, 252-256.

H., \& Rojewski, J. W. (2015). Gender-specific models of work-bound Korean ado- lescents' social supports and career adaptability on subsequent job satisfaction. Journal of Career Development, 42, 149-164. doi:10.1177/0894845314545786

Hartung, P. J., Porfeli, E. J., \& Vondracek, F. W. (2008). Career adaptability in childhood. The Career Development Quarterly, 57(1), 63-74.

Hirschi, A. (2009). Career adaptability development in adolescence: Multiple predictors and effect on sense of power and life satisfaction. Journal of Vocational Behavior, 74, 145-155. doi:10.1016/j.jvb.2009.01.002

Hirschi, A., Herrmann, A., \& Keller, A. C. (2015). Career adaptivity, adaptability, and adapting: A conceptual and empirical investigation. Journal of Vocational Behavior, 87, 1-10. doi:10.1016/j.jvb.2014.11.008

Hlad' o, P., Kvasková, L., Ježek, S., Hirschi, A., \& Macek, P. (2020). Career adaptability and social support of vocational students leaving upper secondary school. Journal of Career Assessment, 28(3), 478-495.

Josselson, R. (1994). Identity and relatedness in the life cycle. In H. A. Bosma, T. L. G. Graafsma, H. D. Grotevant, \& D. J. C. Levita (Eds.), Identity and development: An interdisciplinary approach (pp. 81-102). Thousand Oaks, CA: Sage.

Kenny, M. E., \& Bledsoe, M. (2005). Contributions of the relational context to career adaptability among urban adolescents. Journal of Vocational Behavior, 66, 257-272. doi:10.1016/j.jvb.2004.10.002

Mahamud, I, Y., Che Hassan, N., \& Fakhruddin, F. (2018). Penglibatan ibu bapa dalam aktiviti pembelajaran anak di rumah Dan hubungannya dengan pencapaian akademik murid Sekolah agama bantuan kerajaan (SABK). E-Jurnal Penyelidikan dan Inovasi, 5(1), 42-62.

Malik, S. (2020). Strategies to solve communication barriers between parents and teachers of visually impaired learners in Pakistan. International Journal of Curriculum and Instruction, 12(2), 42-62.

Obi, M. C., Oye, N. D., Mohd, T. N., \& Bernice, A. (2012). The Impact of ICT on Career Counseling Services : A case Study of Nigerian Secondary Schools. International Journal of Evaluation and Research in Education (IJERE).

Öztemel, K., \& Y1ldız-Akyol, E. (2019). The predictive role of happiness, social support, and future time orientation in career adaptability. Journal of Career Development.

Parker, P. (2002). Working with the intelligent career model. Journal of Employment Counseling, 39, 83-96.

Porfeli, E. J., \& Savickas, M. L. (2012). Career Adapt-Abilities Scale-USA Form: Psy- chometric properties and relation to vocational identity. Journal of Vocational Behavior, 80, 748-753. doi:10.1016/j.jvb.2012.01.009

Rashid, A. M. (2011). Career Development interventions in technical and vocational schools in Malaysia. The Journal of Human Resource and Adult Learning, 7(2), 23-33.

Savickas, M. L. (1999). The transition from school to work: A developmental perspective. The Career Development Quarterly, 47, 326-336. doi:10.1002/j.2161-0045.1999. tb00741.x

Savickas, M. L. (2011). New questions for vocational psychology: Premises, paradigms, and practices. Journal of Career Assessment, 3, 251-258.

Savickas, M. L. (2013). Career construction theory and practice. In R. W. Lent \& S. D. Brown (Eds.), Career development and counseling: Putting theory and research to work (2nd ed., pp. 144-180). Hoboken, NJ: Wiley. 
Savickas, M. L., Nota, L., Rossier, J., Dauwalder, J. P., Duarte, M. E., Guichard, J., .. . van Vianen, A. E. M. (2009). Life designing: A paradigm for career construction in the 21st century. Journal of Vocational Behavior, 75, 239-250. doi:10.1016/j.jvb.2009.04.004

Sekaran, U. (2003). Research and Markets: Research Methods for Business - A Skill Building Approach. John Wiley \& Sons. https://doi.org/http://dx.doi.org/10.1108/17506200710779521

Statistik Pendidikan Tinggi. (2018). Kajian Pengesanan Graduan. Kementerian Pendidikan Malaysia. Retrieved from https://www.moe.gov.my/en/muat-turun/laporan-dan-statistik/pendidikantinggi/buku-perangkaan/2018-10/2408-statistik-pendidikan-tinggi-2018-bab-7-pdf/file

Sullivan, S. E., \& Baruch, Y. (2009). Advances in career theory and research: a critical review and agenda for future exploration. Journal of Management, 35(6), 1542- 1571. doi:10.1177/0149206309350082

Turan, E., Celik, E., \& Turan, M. E. (2014). Perceived social support as predictors of adolescents career exploration. Australian Journal of Career Development, 23(3), 119-124. doi:10.1177/1038416214535109

Wang, Z., \& Fu, Y. (2015). Social support, social comparison, and career adaptability: A moderated mediation model. Journal of Social Behavior and Personality, 43, 649-660.

Yousefi, Z., Abedi, M., Baghban, I., Eatemadi, O., \& Abedi, A. (2011). Personal and situational variables, and career concerns: predicting career adaptability in young adults. The Spanish Journal of Psychology, 14(1), 23 